Original article

\title{
Long-term treatment with chaethomellic acid A reduces glomerulosclerosis and arteriolosclerosis in a rat model of chronic kidney disease
}

\author{
António Nogueiraa ${ }^{\mathrm{a}, \mathrm{b}}$, Helena Vala ${ }^{\mathrm{c}, \mathrm{d}}$, Carmen Vasconcelos-Nóbrega ${ }^{\mathrm{c}, \mathrm{d}}$, \\ Ana Isabel Faustino-Rocha ${ }^{\mathrm{a}, \mathrm{e}}$, Carlos André Pires ${ }^{\mathrm{f}}$, Aura Colaço ${ }^{\mathrm{a}, \mathrm{g}}$, Paula Alexandra Oliveira ${ }^{\mathrm{a}, \mathrm{e}}$, \\ Maria João Pires ${ }^{\mathrm{a}, \mathrm{e}, *}$ \\ a Department of Veterinary Sciences, School of Agrarian and Veterinary Sciences, University of Trás-os-Montes and Alto Douro (UTAD), Vila Real, Portugal \\ b Department of Therapeutic and Diagnostic Technologies, Polytechnic Institute of Bragança (IPB), Bragança, Portugal \\ c Agrarian School of Viseu, Polytechnic Institute of Viseu, Viseu, Portugal \\ d Center for the Study of Education, Technologies and Health, Polytechnic Institute of Viseu, Viseu, Portugal \\ e Center for the Research and Technology of Agro-Environmental and Biological Science (CITAB), UTAD, Vila Real, Portugal \\ ${ }^{\mathrm{f}}$ Center for Mathematics, UTAD, Vila Real, Portugal \\ ${ }^{g}$ Animal and Veterinary Research Center (CECAV), UTAD, Vila Real, Portugal
}

\section{A R T I C L E I N F O}

\section{Keywords:}

Wistar rats

$5 / 6$ renal mass reduction model

Chaetomellic acid a

Ha-Ras protein

Renal fibrosis

\begin{abstract}
A B S T R A C T
The high prevalence of end-stage renal disease emphasizes the failure to provide therapies to effectively prevent and/or reverse renal fibrosis. Therefore, the aim of this study was to evaluate the effect of long-term treatment with chaethomellic acid A (CAA), which selectively blocks Ha-Ras farnesylation, on renal mass reduction-induced renal fibrosis. Male Wistar rats were sham-operated (SO) or subjected to 5/6 renal mass reduction (RMR). One week after surgery, rats were placed in four experimental groups: SO:SO rats without treatment $(n=13)$; SO + CAA: SO rats treated with CAA $(n=13)$; RMR:RMR rats without treatment $(n=14)$; and $R M R$ + CAA:RMR rats treated with CAA $(n=13)$. CAA was intraperitoneally administered in a dose of $0.23 \mu \mathrm{g} / \mathrm{kg}$ three times a week for six months. Renal fibrosis was evaluated by two-dimensional ultrasonography and histopathological analysis. The kidneys of the RMR animals treated with CAA showed a significantly decrease in the medullary echogenicity $(\mathrm{p}<0.05$ ) compared with the RMR rats that received no treatment. Glomerulosclerosis and arteriolosclerosis scores were significantly lower $(\mathrm{p}<0.001)$ in the RMR + CAA group when compared with the RMR group. There were no significant differences in interstitial fibrosis, interstitial inflammation and tubular dilatation scores between the RMR + CAA and RMR groups. These data suggest that CAA can be a potential future drug to attenuate the progression of chronic kidney disease.
\end{abstract}

\section{Introduction}

Chronic kidney disease (CKD) is an important challenge for healthcare systems worldwide [1]. The natural course of the CKD is to progress towards end-stage renal disease (ESRD) and death, unless dialysis or transplant is implemented [2]. Regardless of the initial cause, development of renal fibrosis is the hallmark of most progressive CKD [3]. Therefore, targeting the components of the fibrogenic pathways can be a therapeutic approach to inhibit or slow the progression of CKD to ESRD.

The Ras proteins - small monomeric GTPase of $21 \mathrm{kDa}$ - are important mediators in the development of renal fibrosis [4-8] and thereby could be a potential therapeutic target against fibrotic nephropathies. These proteins are located in different plasma-membrane microdomains and subcellular compartments where activate several signalling pathways. The best characterized signalling pathways are: the Ras/Raf/MEK-ERK1/2, which is responsible for the induction of several cellular responses such as cell growth, differentiation and apoptosis; and the Ras/PI3 K/Akt, which is implicated in regulation of cell metabolism, cell motility and promotion of cell survival protecting cells from apoptosis [9-11]. Activation of these signalling pathways has been reported as mediators in renal fibrosis $[4,7,8]$.

\footnotetext{
Abbreviations: CAA, chaethomellic acid A; CKD, chronic kidney disease; ECM, extracellular matrix proteins; EMT, epithelial-to-mesenchymal transition; ESRD, end-stage renal disease;

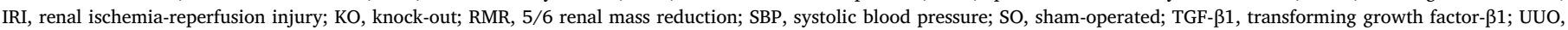
unilateral ureteral obstruction; $\alpha$-SMA, alpha-smooth muscle actin

* Corresponding author at: Department of Veterinary Sciences, University of Trás - os - Montes and Alto Douro, 5001 - 801 Vila Real, Portugal.

E-mail address: joaomp@utad.pt (M.J. Pires).
} 
There are three closely related major isoforms of Ras proteins: Harvey (Ha)-, Kirsten (Ki)-, and neural (N)-Ras, which are expressed in mammalian cells and have different biological effects [9,12-14], namely in fibroblasts biology and fibrotic processes [6,15-17]. It has been reported that depletion of Ha-Ras isoform in cultured fibroblasts obtained from Ha-Ras knock-out (KO) mice up-regulates extracellular matrix proteins (ECM) synthesis and mediates proliferation and migration by modulating PI3 K/Akt and MEK/ERK activation [16,17]. In an in vivo study, fibrosis was lower in $\mathrm{H}$-Ras $\mathrm{KO}$ than in wild type mice after unilateral ureteral obstruction (UUO) [4]. Therefore, inhibition of Ha-Ras isoform could be used as a potential therapeutic strategy to reduce fibrosis development.

Chaetomellic acid A (CAA) has been identified as a highly specific inhibitor of farnesyl transferase [18], which selectively blocks Ha-Ras farnesylation [19]. Sabbatini et al. [20] have demonstrated that pretreatment with CAA of human renal proximal tubular cells or human umbilical vein endothelial cells significantly reduced apoptosis. The same researchers have also observed that in acute renal ischemia-reperfusion injury (IRI) model in rats, CAA administration preserves both renal function and histological damage $[20,21]$. Furthermore, in a rat model of excitotoxic lesion, CAA treatment increased the intracellular concentration of inactive Ha-Ras, leading to a marked decrease of superoxide anion production [19]. In another in vivo study, CAA administration reduced renal damage after UUO in mice [7]. However, up to now, all the studies performed on the effect of CAA in renal fibrosis have been performed in vitro or in rapid models of renal fibrosis such as UUO.

The $5 / 6$ renal mass reduction (RMR) model has been widely used to study CKD. In this model, the development of renal fibrosis is characterized by the progressive development of glomerulosclerosis, tubulointerstitial fibrosis and vascular sclerosis, leading to ESRD [22,23]. Thus, in this study we aimed to evaluate the effect of long-term treatment with CAA on renal fibrosis in rats with RMR, a model similar to renal fibrosis observed in CKD [24].

\section{Materials and methods}

\subsection{Animals and experimental conditions}

Sixty male Wistar rats (weighing approximately $135 \mathrm{~g}$ ) were acquired from Harlan-Interfauna (Barcelona, Spain). Rats were housed in standard cages (Tecniplast, Buguggiate, Italy) with corncob for bedding (Mucedola, Milan, Italy) in a controlled room: 12/12 h' light-dark cycle, temperature $\left(23 \pm 2{ }^{\circ} \mathrm{C}\right)$ and humidity $(50 \pm 10 \%)$; animals were fed with a standard rat chow (Mucedola ${ }^{\circ}$, Milan, Italy) and water ad libitum. All experimental procedures followed the European (European Directive 2010/63/EU) and National (Decree-Law 113/2013) legislation on the protection of the animals used for scientific purposes.

\subsection{Experimental design}

After seven weeks of acclimatization, rats (weighing 359 to $402 \mathrm{~g}$ ) were sham-operated (SO) or submitted to RMR. All surgical procedures were carried out under general anaesthesia (ketamine/xylazine, 70/ $10 \mathrm{mg} / \mathrm{kg}$; intraperitoneally) and aseptic conditions. The animals assigned to the RMR groups $(n=34)$ were subjected to $5 / 6$ RMR by surgical resection through a midline laparotomy, as described previously [25]. The right kidney was exposed, decapsulated and removed. Then, the left kidney was exposed, decapsulated and both the upper and lower poles (two thirds of the left kidney) were resected. Excised kidney and poles were weighed immediately after removal. The sham-operated group rats $(n=26)$ underwent the same abdominal incision and manipulation of the right and the left kidneys without removal of renal mass. Special care was taken to prevent damage to the adrenal glands during the surgeries. The percentage of renal tissue removed was calculated based on the removed tissue, assuming that the right and left kidneys had equal weights. Two days after renal mass reduction, serum creatinine was measured (Daytona ${ }^{\circ} \mathrm{Rx}$, Randox). Rats weights were recorded weekly. Animals were daily observed to assess their general health and mortality.

One week after surgery surviving animals $(n=53)$ were distributed into four groups: SO, SO rats receiving no treatment $(\mathrm{n}=13)$; SO + CAA, SO rats receiving CAA treatment $(n=13)$; RMR, RMR rats receiving no treatment $(n=14)$; RMR + CAA, RMR rats receiving CAA treatment $(n=13)$. Rats from SO groups were distributed randomly and the animals from RMR groups were distributed according to the serum creatinine concentrations and the percentage of the removed renal tissue to ensure equal reduction in renal mass. CAA was intraperitoneally administered $(0.23 \mu \mathrm{g} / \mathrm{Kg}$; Santa Cruz Biotechnology, California, USA) [21] three times a week for six months.

\subsection{Ultrasonographic evaluation}

Six months after the surgical procedure, in the left kidney of each animal was evaluated the mean cortical and medullary echogenicity by ultrasonography using two-dimensional ultrasonography (B mode) as reported previously by Nogueira et al. [26].

\subsection{Renal function assessment}

Blood and urine samples were collected at the sixth month as we have previously described [27]. Plasma creatinine, urinary creatinine and proteinuria were measured using a chemistry analyser (Daytona $\mathrm{Rx}$, Randox) as per manufacturers' instructions. Creatinine clearance was calculated according to standard formula [Uc $\mathrm{x}$ V/Pc, where $\mathrm{Uc}=$ urine creatinine $(\mathrm{mg} / \mathrm{dl}), \mathrm{V}=$ urine volume $(\mathrm{ml} / \mathrm{min} / 100 \mathrm{~g}$ body weight) and Pc $=$ plasma creatinine $(\mathrm{mg} / \mathrm{dl})]$.

\subsection{Animals' sacrifice}

Six months after the surgery, surviving animals were anesthetized with isoflurane. Systolic blood pressure (SBP) was measured through femoral artery catheterization as we have previously described [27]. After that, the rats were sacrificed using an overdose of anaesthesia followed by exsanguination by cardiac puncture as indicated by the Federation of European Laboratory Animal Science Associations [28]. A complete necropsy was performed, either the remnant kidney from RMR rats or both kidneys from SO rats were removed, weighed and examined macroscopically. Relative left kidney weights were calculated as the ratio of the left kidney weight to the rats' total body weight [29].

\subsection{Renal fibrosis evaluation}

Samples were fixed in neutral buffered formalin $10 \%$, embedded in paraffin wax, by routine methods, and $2 \mu \mathrm{m}$ thick sections, including renal cortex and medulla, were stained for routine histopathological diagnosis with Haematoxylin and Eosin (HE), Masson's trichrome and Reticulin special stains. Renal fibrosis was evaluate under light microscopy by two different researchers blindly and scored as previously reported by Asaba et al. [30]: glomerulosclerosis (0: normal; 1: matrix expansion or sclerosis less than 25\%; 2: 26-50\%; 3: 51-75\%; and 4: more than 75\%); interstitial fibrosis (0: normal; 1 : mild fibrosis around vasculature; 2 : mild fibrosis around tubules; 3 : moderate fibrosis with tubular casts or tubular damage; and 4: severe fibrosis with cell infiltration) and arteriolosclerosis (0: normal; 1: medial thickening; 2 : segmental hyalinosis; 3: global hyalinosis; and 4: luminal occlusion with thrombus or infiltrating cells). The interstitial inflammation (presence of aggregates of lymphocytes and neutrophils in the interstitium) and the tubular dilatation (significant increase in luminal diameter, more than two folds, associated with flattening of the epithelial lining) were assessed according to Moubarak et al. [31] (0: not present; 1: minimal damage with rare and small foci; 2 : mild damage 
with few and small foci; and 3: moderate damage with frequent and moderately sized foci). The average of each score was calculated for each rat.

\subsection{Statistical analysis}

Data were analysed with SPSS ${ }^{\circ}$ (version 23 for Windows; IBM Corp., Armonk, NY, USA). Results are presented as mean \pm standard error (SE). The normality of the data was checked with the Shapiro-Wilk test. Statistical differences between groups were assessed by one-way analysis of variance (ANOVA) for independent samples, followed by Tukey HSD post hoc tests, when the data was normally distributed. In the other cases, the Kruskal-Wallis test was used, followed by multiple comparisons by Dunn's procedure. Differences between groups were considered statistically significant if $p<0.05$.

\section{Results}

\subsection{General data and renal function}

During this experimental study, two animals from RMR group and five animals from RMR + CAA group died. However, in the RMR group treated with CAA, the rats died only from the fifth month after RMR. Necropsies were performed on all the animals that died and were not seen macroscopic changes in the kidneys, bladder, heart, lungs, liver and spleen. However, in the last measurements made before the death of the animals they had low body weights, high levels of plasma creatinine, low values of creatinine clearance and an intense proteinuria, indicating a severe renal failure that possibly was the cause of these animals' death. The data from these animals were not included in the final data analysis and the size of the groups was reduced to 12 animals in RMR group and 8 animals in RMR + CAA group. At end of experimental protocol (6 months), body weight was lower in the animals that underwent RMR when compared with the sham-operated control rats; however, only the RMR + CAA group showed a significant decrease in body weight when compared with the sham-operated untreated group $(p<0.05)$ As expected, RMR led to hypertrophy of the remnant kidney. The left kidney weight and left kidney weight/body weight ratio in RMR rats were significantly higher compared to the weight of the intact kidney in sham-operated control ones $(p<0.05)$. Also, as expect, in RMR rats the values of SBP was significantly higher compared with sham-operated control rats $(p<0.05)$; and rats from RMR groups showed clinical signs of CKD characterized by significant reduction in creatinine clearance and significant increase in urinary protein loss in comparison to sham-operated controls rats $(p<0.05)$ (Table 1).

\subsection{Kidney echogenicity}

Renal echogenicity was evaluated in the cortex and medulla of the left kidney in all experimental groups at the end of the study.
Representative ultrasonographic images of the cortex and medulla of the left kidney from all experimental groups are shown in Fig. 1. The echogenicity of cortex and medulla was higher in both RMR groups when compared with sham-operated control groups $(p<0.05)$. The CAA administration decreased the cortical and medullary echogenicity in RMR rats, however only with statistically significance for medullary echogenicity ( $p<0.05$ ) (Fig. 2).

\subsection{Histopathological studies}

The results of the evaluation of glomerulosclerosis, interstitial fibrosis, arteriolosclerosis, interstitial inflammation and tubular dilatation are given in Table 2; and the distribution by different grades of severity in these histological lesions for all experimental groups can be seen in Table 3. Rats from SO groups presented no kidney histological changes: kidney tissue displayed a normal morphology with intact glomeruli and tubules (Fig. 3a-f), although some animals showed minimal to mild interstitial inflammation (Table 3). The RMR rats that received no treatment showed severe glomerulosclerosis, interstitial fibrosis, interstitial inflammation, arteriolosclerosis and tubular dilatation (Tables 2 and 3; Fig. $3 \mathrm{~g}-\mathrm{i}$ ). In the RMR rats that received CAA, the severity of glomerulosclerosis and arteriolosclerosis was significantly reduced compared with RMR rats that received no treatment. The degree of interstitial fibrosis, interstitial inflammation and tubular dilatation was also reduced in the RMR rats that received CAA compared with the RMR rats that received no treatment; however, these differences were not statistically significant (Tables 2 and 3; Fig. 3j-1).

\section{Discussion}

Development of renal fibrosis is the hallmark of most progressive CKD, regardless of its primary aetiology [3]. Therefore, treatment strategies aimed at preventing or slowing its devastating sequelae and progression to ESRD are of greatest importance.

Some studies highlight the importance of Ha-Ras isoform in the development of fibrosis $[4,16,17]$. Therefore, we have evaluated the effect of CAA, which selectively blocks Ha-Ras farnesylation [19], on renal fibrosis. To date, relatively few studies have assessed the effects of the CAA in experimental models of kidney diseases [7,20,21,27]. To our knowledge this is the first study that evaluated the effect of long-term CAA treatment on renal fibrosis in rats with progressive renal disease. In the present study, we have demonstrated that CAA $(0.23 \mu \mathrm{g} / \mathrm{Kg}$, three times a week, for six months) attenuate renal fibrosis, particularly glomerulosclerosis. Our results confirm the capability of CAA to reduce renal fibrosis observed in the IRI and UUO rodent models by Sabbatini et al. [20,21] and Rodriguez-Peña et al. [7], respectively.

In most patients, CKD progresses to an end point with common histological features characterized by accumulation of ECM in glomeruli and interstitium, which leads to generalized fibrosis and tubular atrophy [32]. Therefore, the acceptable animal model for the study of renal fibrosis should provide the development of glomerulosclerosis and

Table 1

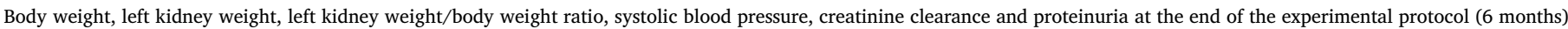
(mean \pm standard error).

\begin{tabular}{|c|c|c|c|c|c|}
\hline & $\mathrm{SO}(\mathrm{n}=13)$ & $\mathrm{SO}+\mathrm{CAA}(\mathrm{n}=13)$ & $\operatorname{RMR}(\mathrm{n}=12)$ & $\mathrm{RMR}+\mathrm{CAA}(\mathrm{n}=8)$ & $p^{1}$ \\
\hline Body weight $(g)$ & $560 \pm 16^{\mathrm{a}}$ & $550 \pm 10^{\mathrm{ab}}$ & $516 \pm 13^{\mathrm{ab}}$ & $503 \pm 12^{\mathrm{b}}$ & 0.015 \\
\hline Left Kidney weight $(\mathrm{g})$ & $1.35 \pm 0.03^{\mathrm{a}}$ & $1.29 \pm 0.03^{\mathrm{a}}$ & $2.32 \pm 0.14^{\mathrm{b}}$ & $1.97 \pm 0.12^{\mathrm{b}}$ & $<0.001$ \\
\hline Left Kidney weight/Body weight ratio (\%) & $0.24 \pm 0.01^{\mathrm{a}}$ & $0.24 \pm 0.01^{\mathrm{a}}$ & $0.45 \pm 0.03^{\mathrm{b}}$ & $0.39 \pm 0.03^{\mathrm{b}}$ & $<0.001$ \\
\hline Systolic blood pressure (mmHg) & $148.22 \pm 6.36^{\mathrm{a}}$ & $146.00 \pm 5.32^{\mathrm{a}}$ & $202.22 \pm 9.61^{\mathrm{b}}$ & $184.29 \pm 9.79^{\mathrm{b}}$ & $<0.001$ \\
\hline Creatinine clearance $(\mathrm{ml} / \mathrm{min})$ & $1.56 \pm 0.04^{\mathrm{a}}$ & $1.45 \pm 0.09^{\mathrm{a}}$ & $0.73 \pm 0.10^{\mathrm{b}}$ & $0.92 \pm 0.11^{\mathrm{b}}$ & $<0.001$ \\
\hline Proteinuria (g/day) & $0.105 \pm 0.006^{\mathrm{a}}$ & $0.117 \pm 0.09^{\mathrm{a}}$ & $3.167 \pm 0.410^{\mathrm{b}}$ & $2.467 \pm 0.758^{\mathrm{b}}$ & $<0.001$ \\
\hline
\end{tabular}

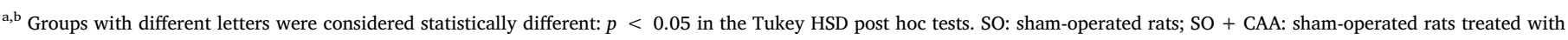
chaetomellic acid A; RMR: rats with 5/6 renal mass reduction; RMR + CAA: rats with 5/6 renal mass reduction treated with chaetomellic acid A.

${ }^{1}$ Significance value of the ANOVA. 


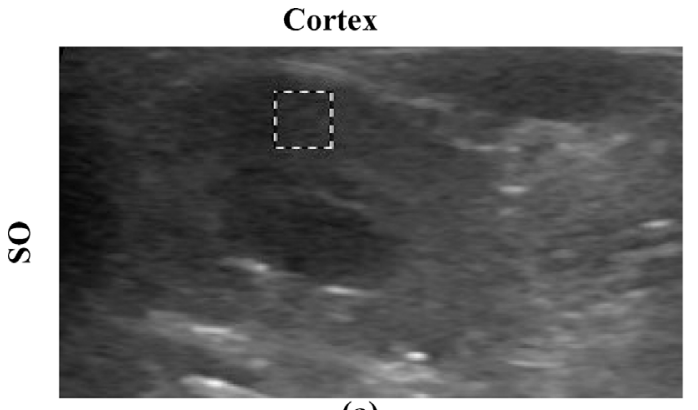

(a)

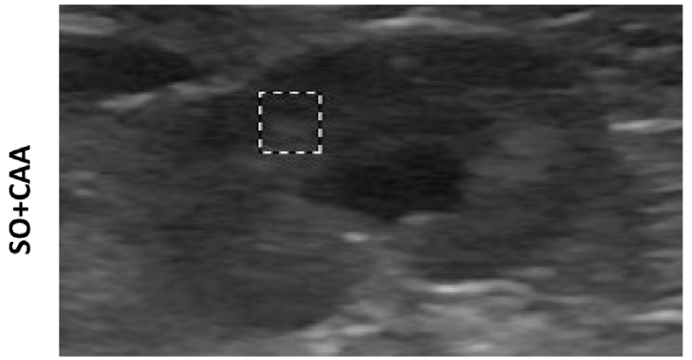

(c)

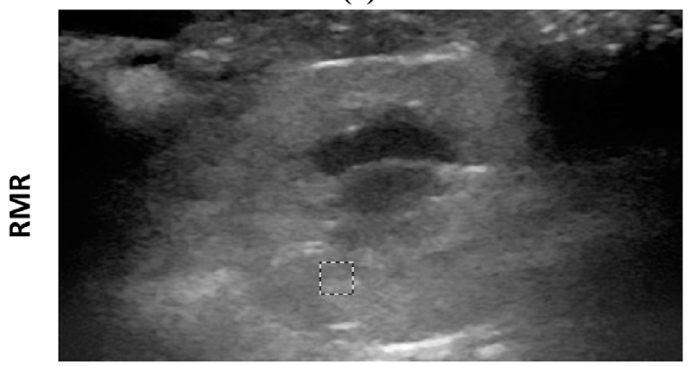

(e)

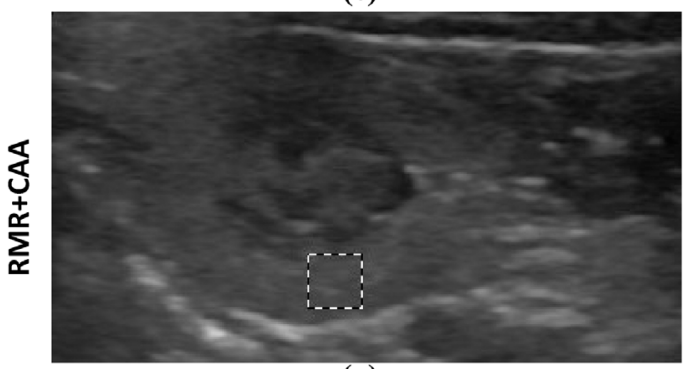

(g)

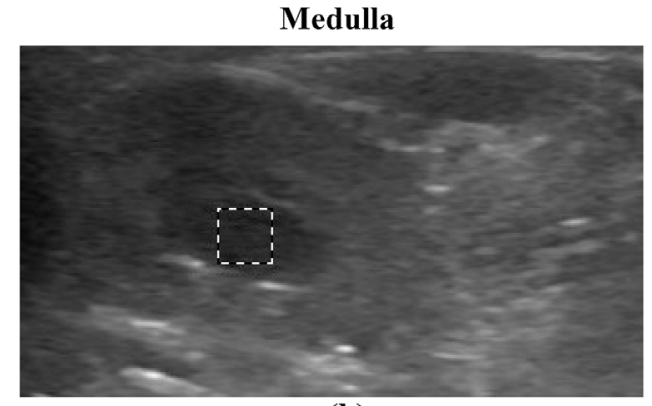

(b)

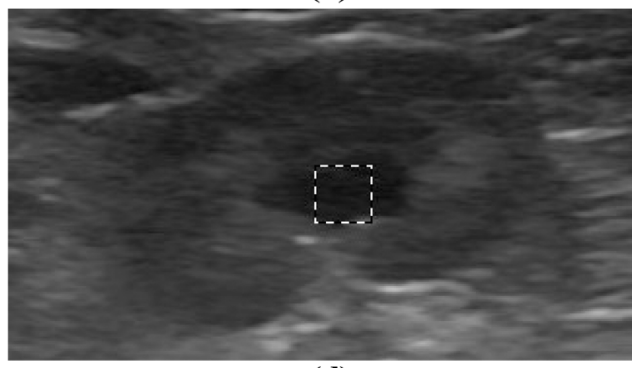

(d)

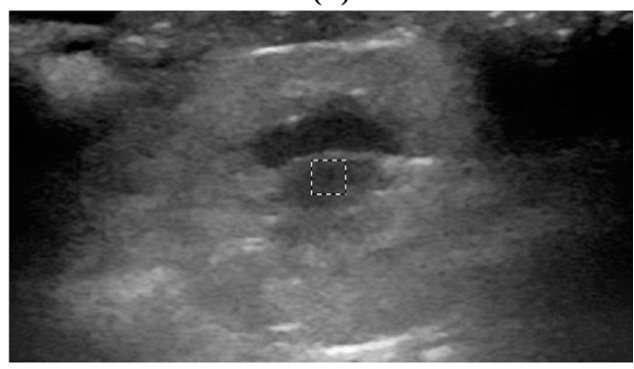

(f)

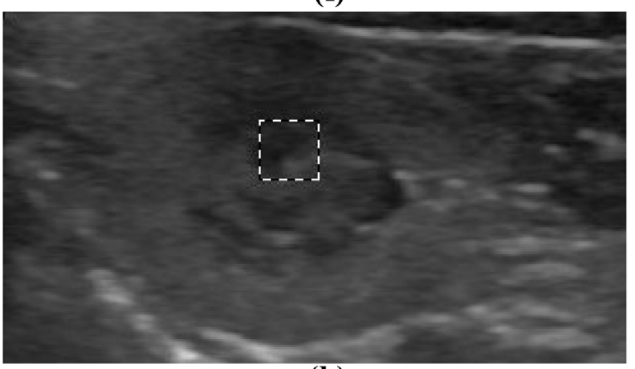

(h)
Fig. 1. Ultrasonographic images showing the measurement of the mean pixels (echogenicity) in the cortex (a, c, e, g) and medulla (b, d, f, h) of the left kidney of the sham-operated rats (SO) (a and b), shamoperated rats treated with chaetomellic acid A (SO + CAA) (c and d), rats with 5/6 renal mass reduction (RMR) (e and $f$ ) and rats with 5/6 renal mass reduction treated with chaetomellic acid A (RMR + CAA) ( $\mathrm{g}$ and h).
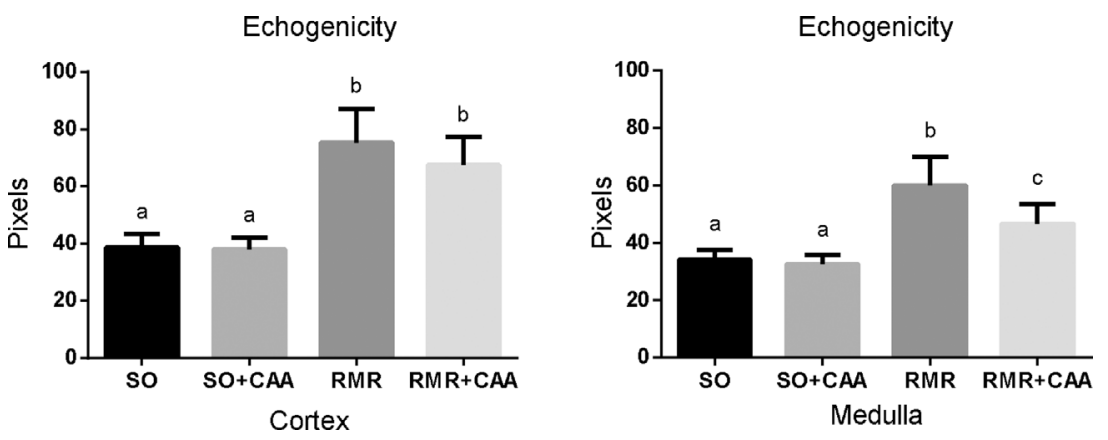

Fig. 2. Echogenicity of the cortex and medulla of the left kidney in all experimental groups at the end of the experimental protocol (6 months). SO: sham-operated rats; SO + CAA: sham-operated rats treated with chaetomellic acid A; RMR: rats with $5 / 6$ renal mass reduction; RMR + CAA: rats with 5/6 renal mass reduction treated with chaetomellic acid A (Kruskal-Wallis Test: $\mathrm{p}<0.05$ for cortex and medulla. ${ }^{\mathbf{a}, \mathbf{b}, \mathbf{c}}$ Groups with different letters were considered statistically different: $p<0.05$ in the multiple comparisons by Dunn's procedure).

interstitial fibrosis to a comparable extent to what is observed in human medicine. One of the most commonly animal models used to study renal disease progression is the 5/6 RMR in rats, which we used to evaluate the effect of CAA on renal fibrosis.

In this animal model, the increase in the glomerular filtration rate and blood flow associated with glomerular hypertension is followed by progressive deterioration of renal function accompanied by severe proteinuria and by structural renal changes such as glomerulosclerosis, tubulointerstitial fibrosis and vascular sclerosis [22,23]. In this study, after six months of RMR rats showed typical features of CKD: systemic hypertension, renal failure, proteinuria and renal fibrosis, which proved that RMR had been successfully performed.

In the present study, no deaths were observed in SO groups. However, among the RMR groups, the mortality was higher in the rats 
Table 2

Scores of renal fibrosis, inflammation and tubular dilatation at the end of the experimental protocol (6 months) (mean \pm standard error).

\begin{tabular}{|c|c|c|c|c|c|}
\hline Scores & SO $(n=13)$ & $\mathrm{SO}+\mathrm{CAA}(\mathrm{n}=13)$ & $\mathrm{RMR}(\mathrm{n}=12)$ & $\mathrm{RMR}+\mathrm{CAA}(\mathrm{n}=8)$ & $p^{1}$ \\
\hline Glomerulosclerosis score & $0.00 \pm 0.00^{\mathrm{a}}$ & $0.00 \pm 0.00^{\mathrm{a}}$ & $3.42 \pm 0.19^{b}$ & $1.88 \pm 0.35^{c}$ & $<0.001$ \\
\hline Interstitial fibrosis score & $0.00 \pm 0.00^{\mathrm{a}}$ & $0.00 \pm 0.00^{\mathrm{a}}$ & $3.25 \pm 0.14^{\mathrm{b}}$ & $2.17 \pm 0.35^{\mathrm{b}}$ & $<0.001$ \\
\hline Arteriolosclerosis score & $0.00 \pm 0.00^{\mathrm{a}}$ & $0.00 \pm 0.00^{\mathrm{a}}$ & $1.83 \pm 0.37^{\mathrm{b}}$ & $0.50 \pm 0.38^{\mathrm{a}}$ & $<0.001$ \\
\hline Interstitial inflammation score & $0.31 \pm 0.13^{\mathrm{a}}$ & $0.15 \pm 0.15^{\mathrm{a}}$ & $3.00 \pm 0.00^{\mathrm{b}}$ & $2.50 \pm 0.27^{b}$ & $<0.001$ \\
\hline Tubular dilatation score & $0.00 \pm 0.00^{\mathrm{a}}$ & $0.00 \pm 0.00^{\mathrm{a}}$ & $3.00 \pm 0.00^{\mathrm{b}}$ & $1.88 \pm 0.35^{\mathrm{b}}$ & $<0.001$ \\
\hline
\end{tabular}

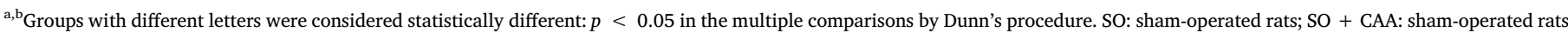
treated with chaetomellic acid A; RMR: rats with 5/6 renal mass reduction; RMR + CAA: rats with 5/6 renal mass reduction treated with chaetomellic acid A.

${ }^{1}$ Significance value of the Kruskal-Wallis Test.

Table 3

Distribution by different grades of severity in the different histological lesions.

\begin{tabular}{|c|c|c|c|c|}
\hline Histological lesion & SO $(n=13)$ & $\mathrm{SO}+\mathrm{CAA}(\mathrm{n}=13)$ & $\operatorname{RMR}(\mathrm{n}=12)$ & $\mathrm{RMR}+\mathrm{CAA}(\mathrm{n}=8)$ \\
\hline \multicolumn{5}{|l|}{ Glomerulosclerosis } \\
\hline 0. Normal & $13(100.0 \%)$ & $13(100.0 \%)$ & $0(0.0 \%)$ & $0(0.0 \%)$ \\
\hline 1. $\leq 25 \%$ & $0(0.0 \%)$ & $0(0.0 \%)$ & $0(0.0 \%)$ & $3(37.5 \%)$ \\
\hline 2. $26-50 \%$ & $0(0.0 \%)$ & $0(0.0 \%)$ & $1(8.3 \%)$ & $4(50.0 \%)$ \\
\hline 3. $51-75 \%$ & $0(0.0 \%)$ & $0(0.0 \%)$ & $5(41.7 \%)$ & $0(0.0 \%)$ \\
\hline 4. $>75 \%$ & $0(0.0 \%)$ & $0(0.0 \%)$ & $6(50.0 \%)$ & $1(12.5 \%)$ \\
\hline \multicolumn{5}{|l|}{ Interstitial fibrosis } \\
\hline 0. Normal & $13(100.0 \%)$ & $13(100.0 \%)$ & $0(0.0 \%)$ & $0(0.0 \%)$ \\
\hline 1. Mild fibrosis around vasculature & $0(0.0 \%)$ & $0(0.0 \%)$ & $0(0.0 \%)$ & $2(25.0 \%)$ \\
\hline 2. Mild fibrosis around tubules & $0(0.0 \%)$ & $0(0.0 \%)$ & $0(0.0 \%)$ & $4(50.0 \%)$ \\
\hline 3. Moderate fibrosis with tubular casts or tubular damage & $0(0.0 \%)$ & $0(0.0 \%)$ & $9(75.0 \%)$ & $1(12.5 \%)$ \\
\hline 4. Severe fibrosis with cell infiltration & $0(0.0 \%)$ & $0(0.0 \%)$ & $3(25.0 \%)$ & $1(12.5 \%)$ \\
\hline \multicolumn{5}{|l|}{ Arteriolosclerosis } \\
\hline 0. Normal & $13(100.0 \%)$ & $13(100.0 \%)$ & $1(8.3 \%)$ & $6(75.0 \%)$ \\
\hline 1. Medial thickening & $0(0.0 \%)$ & $0(0.0 \%)$ & $6(50.0 \%)$ & $1(12.5 \%)$ \\
\hline 2. Segmental hyalinosis & $0(0.0 \%)$ & $0(0.0 \%)$ & $0(0.0 \%)$ & $0(0.0 \%)$ \\
\hline 3. Global hyalinosis & $0(0.0 \%)$ & $0(0.0 \%)$ & $4(33.3 \%)$ & $1(12.5 \%)$ \\
\hline 4. Luminal occlusion with thrombus or infiltrating cells & $0(0.0 \%)$ & $0(0.0 \%)$ & $1(8.3 \%)$ & $0(0.0 \%)$ \\
\hline \multicolumn{5}{|l|}{ Interstitial inflammation } \\
\hline 0. Not present & $9(69.2 \%)$ & $12(92.3 \%)$ & $0(0.0 \%)$ & $0(0.0 \%)$ \\
\hline 1. Minimal with rare and small foci & $4(30.8 \%)$ & $0(0.0 \%)$ & $0(0.0 \%)$ & $1(12.5 \%)$ \\
\hline 2. Mild damage with few and small foci & $0(0.0 \%)$ & $1(7.7 \%)$ & $0(0.0 \%)$ & $2(25.0 \%)$ \\
\hline 3. Moderate damage with frequent and moderately sized foci & $0(0.0 \%)$ & $0(0.0 \%)$ & $12(100.0 \%)$ & $5(62.5 \%)$ \\
\hline \multicolumn{5}{|l|}{ Tubular dilatation } \\
\hline 0 Not present & $13(100.0 \%)$ & $13(100.0 \%)$ & $0(0.0 \%)$ & $1(12.5 \%)$ \\
\hline 1 Minimal & $0(0.0 \%)$ & $0(0.0 \%)$ & $0(0.0 \%)$ & $1(12.5 \%)$ \\
\hline 2 Mild & $0(0.0 \%)$ & $0(0.0 \%)$ & $0(0.0 \%)$ & $4(50.0 \%)$ \\
\hline 3 Moderate & $0(0.0 \%)$ & $0(0.0 \%)$ & $12(100.0 \%)$ & $2(25.0 \%)$ \\
\hline
\end{tabular}

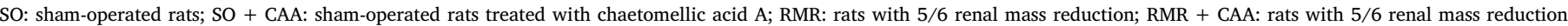
treated with chaetomellic acid A.

treated with CAA, despite the deaths had occurred only after the fifth month after RMR. According to Qian et al. [33], CAA has a reduced offtarget toxicity relative to others farnesyltransferase inhibitors. In fact, as we have previously discussed [27], we did not observe adverse effects after the administration of CAA to rats. However, possibly chronic administration of CAA $(0.23 \mu \mathrm{g} / \mathrm{kg}$ three times a week) may have some toxicity in rats with CKD, while in healthy animals, administration of CAA is innocuous.

Renal fibrosis was evaluated by ultrasonography and histopathological analysis. Ultrasonography is a real-time imaging technique, noninvasive and non-nephrotoxic [34]. An increase of renal echogenicity is considered an indicator of renal fibrosis [35]. In fact, we have previous observed that the cortical and medullary echogenicity is a good marker of fibrosis in the 5/6 RMR model [26]. In this study, the kidneys of RMR animals treated with CAA showed a decrease in the cortical and medullary echogenicity compared with RMR rats that received no treatment; however, the difference was only statistically significant for medullary echogenicity. So, the results obtained by ultrasonography suggest that CAA has a beneficial effect on renal fibrosis. These results are in agreement with those obtained in histopathological studies, in which we observed that in comparison with RMR group, the kidneys from RMR + CAA group showed significantly reduced glomerulosclerosis and arteriolosclerosis. Kidneys from RMR + CAA group also exhibited less interstitial fibrosis, interstitial inflammation and tubular dilatation.

Histopathological studies of renal tissue after RMR reveal the presence of three phases: rapid hypertrophic phase (2 to 4 weeks after RMR); phase with minimal histological changes (4 to 10 weeks); and the development of segmental glomerular sclerosis and tubulointerstitial fibrosis (after 10 weeks) [36]. Several authors have observed that during the different phases numerous molecules such as cytokines and growth factors [37-39], growth factor receptors [38], and extracellular matrix glycoproteins [40] are overexpressed in renal tissue. In this model, was also observed the activation of the Raf/MAPKs-ERK [41] and PI3 K/Akt [42] pathways - the mainly Ras signalling pathways. Activation of Ras and its signalling pathways Raf/MEK-ERK1/2 and PI3 K/Akt has been described as mediators in progressive renal damage $[43,44]$. In a model of renal fibrosis induced by UUO, renal fibrosis was associated to Ras, ERK, and Akt activations, with main involvement of ERK1/2 in apoptotic events and Akt in proliferative and fibrotic 


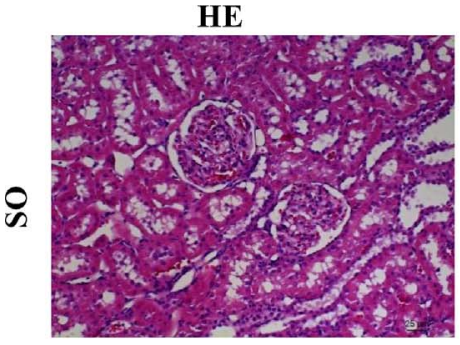

(a)

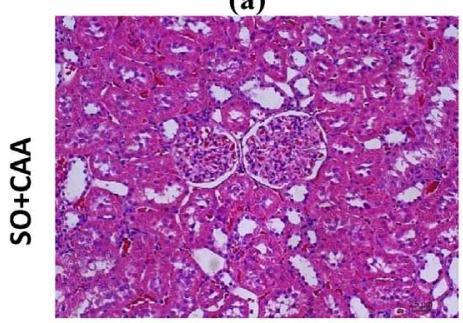

(d)

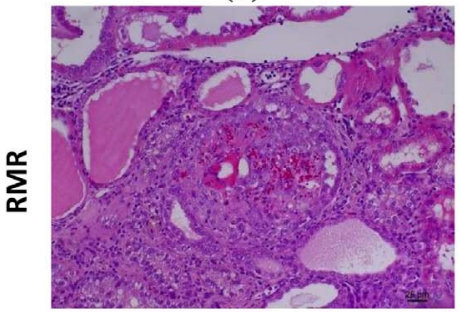

(g)

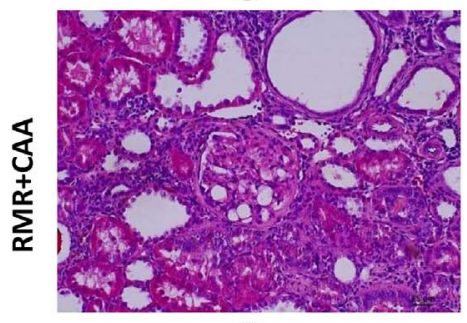

(j)

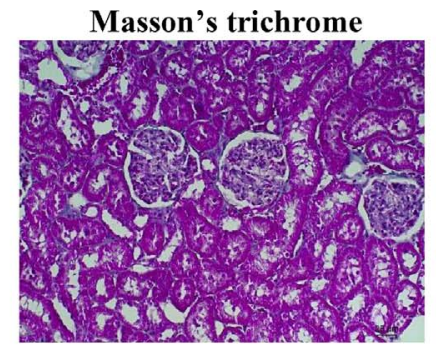

(b)

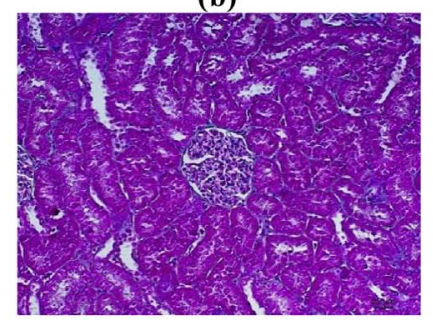

(e)

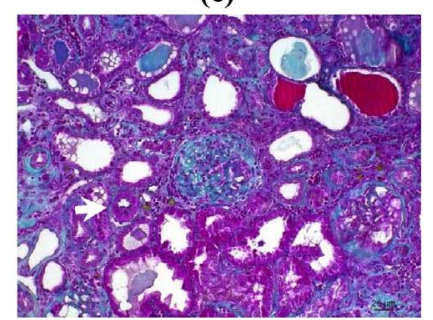

(h)

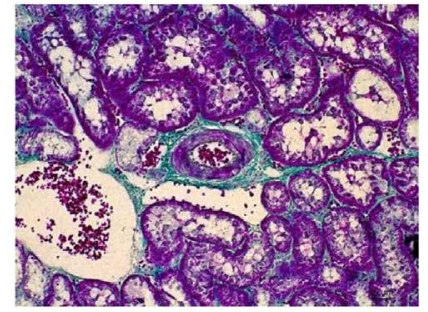

(k)

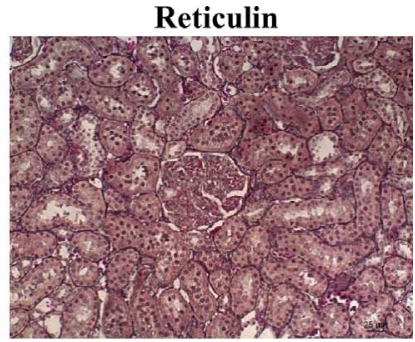

(c)

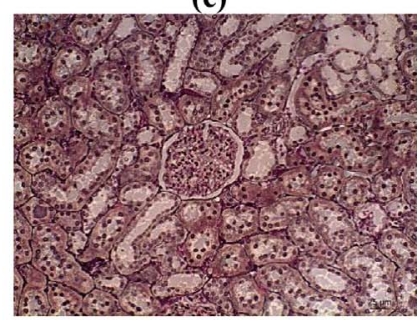

(f)

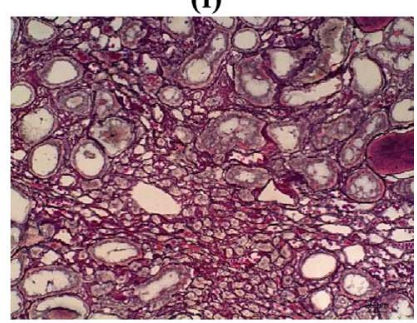

(i)

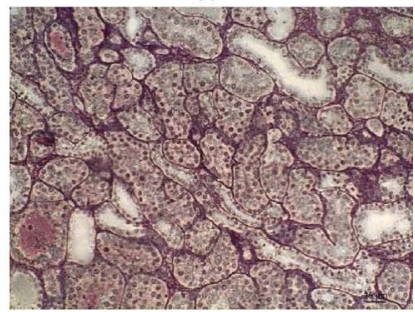

(l)
Fig. 3. Representative kidney sections from sham-operated rats (SO), sham-operated rats treated with chaetomellic acid A (SO + CAA), rats with $5 / 6$ renal mass reduction (RMR) and rats with 5/6 renal mass reduction treated with chaetomellic acid A (RMR + CAA) stained with Haematoxylin and Eosin (HE), Masson's trichrome and reticulin stain. SO group: a, b and c - normal kidney morphology $(\times 200)$; SO + CAA: d, $\mathrm{e}$ and $\mathrm{f}$ - normal kidney morphology ( $\times 200)$; RMR: g - glomerulosclerosis (grade 4) $(\times 200) ; \mathrm{h}$ - glomerulosclerosis (grade 4$)$ and arteriolosclerosis (arrow; grade 3) $(\times 200)$; i - interstitial fibrosis (grade 3 ) $(\times 200)$; and RMR + CAA: j - glomerulosclerosis (grade 2); note also the interstitial inflammation (grade 3$)(\times 200)$; $\mathrm{k}$ - arteriolosclerosis (grade 0$)(\times 200)$; 1 - interstitial fibrosis (grade 2$)(\times 200)$. response [45]. Many growth factors are known to activate intracellular signalling pathways that converge on Ras activation, including transforming growth factor- $\beta 1$ (TGF- $\beta 1$ ) $[9,10]$. The production of TGF- $\beta 1$, both by intrinsic renal cells and infiltrated inflammatory cells, plays a key role in the pathological deposition of extracellular matrix after damage to renal tissue [46]. There is a close relationship between TGF$\beta 1$, Ras signalling pathways and epithelial-to-mesenchymal transition (EMT). EMT plays an important role in the renal fibrosis $[47,48]$. Grande et al. [4] demonstrated in the UUO model performed in mice the relationship between H-Ras and EMT in the kidney and its contribution to the development of renal fibrosis. These authors observed that Ha-Ras deficiency reduces fibrogenesis, activation of Akt, the amount of activated myofibroblasts, and EMT inducers. It also impairs interstitial fibroblast proliferation and decreases TGF- $\beta 1$-induced proliferation and motility in fibroblasts. CAA administration decreased Ras downstream signalling pathways, MAPK-ERK1/2 and PI3 K/Akt, as well as alpha-smooth muscle actin ( $\alpha$-SMA) accumulation (a marker for myofibroblasts) in UUO kidneys [7]. In addition, it has been reported that the inhibition of farnesylation by CAA inhibits Ras/ERK1/2 pathway and significantly reduces acute postischemic renal injury in rats [20]. Thus, through the modulation of Raf/MEK/ERK and PI3K-Akt pathways, CAA may have attenuate RMR-induced renal fibrosis.

In 5/6 RMR, the presence of infiltrated cells plays an essential role in the progression of renal parenchymal lesion [49,50]. An abnormal, persistent inflammatory response may lead to increased synthesis and deposition of ECM with subsequent fibrosis [51]. It was also observed that inflammation can induce EMT [52]. In this study, the interstitial inflammation score was higher in RMR group compared with RMR + CAA group, although this difference was not statistically significant. Therefore, this higher infiltration of inflammatory cells present in the kidney samples of animals belonging to the RMR group may have contributed to a much more pronounced development of renal fibrosis in this group.

Another potential mechanism responsible for the beneficial effects of CAA on renal fibrosis could involve the reduction of oxidative stress. Oxidative stress resulting in generation of reactive oxygen species (ROS), mainly in the form of superoxide and hydrogen peroxide, plays a significant role in the initiation and progression of renal disease $[53,54]$. NADPH oxidase has been identified as the enzyme system most responsible for superoxide generation by adventitial fibroblasts $[55,56]$ and it is recognized as a key mediator of cell proliferation, matrix accumulation [57,58], and EMT [52] in renal disease. Activated Ha-Ras isoform increase intracellular levels of ROS via up-regulation of the plasma membrane NADPH oxidase [59-61]. CAA inhibits Ras/ERK1/2 pathway and protects human renal proximal tubular cells from oxidative stress-induced cell death [20]. Furthermore, CAA administration in rats, after brain damage induced by an excitotoxic stimulus, significantly reduced superoxide production [19]. Also, an in our previous study [27], we have observed that CAA attenuate 5/6 RMR-induced oxidative stress in rats. Oxidative stress plays an important role in renal 
injury induced by $5 / 6$ RMR $[62,63]$. Thus, the reduction of oxidative stress by CAA may also have contributed to the decrease of renal fibrosis seen in the rats treated with CAA.

\section{Conclusion}

Under our experimental conditions, CAA $(0.23 \mu \mathrm{g} / \mathrm{Kg}$, three times a week, for six months) reduced renal fibrosis, mainly glomerulosclerosis and arteriolosclerosis, in a rat model of CKD. Although further studies are necessary, the data of this study suggests that the inhibition of farnesylation of Ha-Ras protein by CAA can be a possible new therapeutic target to attenuate the progression of CKD. The precise mechanisms by which CAA prevents the progression of renal fibrosis cannot be elucidated by this study. However, on the basis of previous studies we can suggest that its protective effects on renal fibrosis observed in this study may be based mainly on its ability to modulate Raf/ MEK/ERK and PI3K-Akt pathways and consequently cell proliferation and EMT. In this study, the mortality was higher in the rats with CKD treated with CAA, although no adverse effects were observed in shamoperated treated rats. These data highlight the need for more studies on the CAA clinical toxicity and safety.

\section{Conflicts of interest}

None

\section{Acknowledgments}

This work is supported by: European Investment Funds by FEDER/ COMPETE/POCI- Operacional Competitiveness and Internacionalization Programme, under Project POCI-01-0145-FEDER-006958 and National Funds by FCT - Portuguese Foundation for Science and Technology, under the project UID/AGR/04033/2013.

\section{References}

[1] K.T. Mills, Y. Xu, W. Zhan, J.D. Bundy, C.-S. Chen, T.N. Kelly, J. Chen, J. He, A systematic analysis of worldwide population-based data on the global burden of chronic kidney disease in 2010, Kidney Int. 88 (2015) 950-957.

[2] J.M. López-Novoa, A.B. Rodríguez-Peña, B. Ortiz, C. Martínez-Salgado, F.J. López Hernández, Etiopathology of chronic tubular, glomerular and renovascular nephropathies: clinical implications, J. Transl. Med. 9 (2011) 1-26.

[3] A. Bohle, G.A. Muller, M. Wehrmann, S. Mackensen-Haen, J.C. Xiao, Pathogenesis of chronic renal failure in the primary glomerulopathies, renal vasculopathies, and chronic interstitial nephritides, Kidney Int. 54 (1996) S2-S9.

[4] M.T. Grande, I. Fuentes-Calvo, M. Arévalo, F. Heredia, E. Santos, C. MartínezSalgado, D. Rodríguez-Puyol, M.A. Nieto, J.M. López-Novoa, Deletion of H-ras decreases renal fibrosis and myofibroblast activation following ureteral obstruction in mice, Kidney Int. 77 (2010) 509-518.

[5] J.-H. Wang, L.J. Newbury, A.S. Knisely, B. Monia, B.M. Hendry, C.C. Sharpe, Antisense knockdown of kras inhibits fibrosis in a rat model of unilateral ureteric obstruction, Am. J. Pathol. 180 (2012) 82-90.

[6] I. Fuentes-Calvo, P. Crespo, E. Santos, J.M. López-Novoa, C. Martínez-Salgado, The small GPTase N-Ras regulates extracellular matrix synthesis, proliferation and migration in fibroblasts, Biochim. Biophys. Acta 1833 (2013) 2734-2744.

[7] A.B. Rodríguez-Peña, I. Fuentes-Calvo, N.G. Docherty, M. Arévalo, M.T. Grande, N. Eleno, F. Pérez-Barriocanal, J.M. López-Novoa, Effect of angiotensin II and small GPTase Ras signaling pathway inhibition on early renal changes in a murine model of obstructive nephropathy, Biomed. Res. Int. (2014), http://dx.doi.org/10.1155/ 2014/124902.

[8] J.M. Muñoz-Félix, I. Fuentes-Calvo, C. Cuesta, N. Eleno, P. Crespo, J.M. LópezNovoa, C. Martínez-Salgado, Absence of K-Ras reduces proliferation and migration but increases extracellular matrix synthesis in fibroblasts, J.Cell Physiol. 231 (2016) 2224-2235.

[9] Y. Takai, T. Sasaki, T. Matozaki, Small GTP-binding proteins, Physiol. Rev. 81 (2001) 153-208.

[10] R.S. Midgley, D.J. Kerr, Ras as a target in cancer therapy, Crit. Rev. Oncol. Hematol. 44 (2002) 109-120.

[11] J. Downward, Targeting RAS signalling pathways in cancer therapy, Nat. Rev. Cancer 3 (2003) 11-22.

[12] G.W. Reuther, C.J. Der, The ras branch of small GTPases: ras family members don't fall far from the tree, Curr. Opin. Cell. Biol. 12 (2000) 157-165.

[13] A. Ehrhardt, G.R. Ehrhardt, X. Guo, J.W. Schrader, Ras and relatives-job sharing and networking keep an old family together, Exp. Hematol. 30 (2002) 1089-1106.

[14] B.M. Hendry, A. Khwaja, Q.Y. Qu, S.J. Shankland, Distinct functions for ras GTPases in the control of proliferation and apoptosis in mouse and human mesangial cells, Kidney Int. 69 (2006) 99-104.

[15] C.C. Sharpe, M.E. Dockrell, R. Scott, M.I. Noor, L.M. Cowsert, B.P. Monia, B.M. Hendry, Evidence of a role for Ki-Ras in the stimulated proliferation of renal fibroblasts, J. Am. Soc. Nephrol. 10 (1999) 1186-1192.

[16] C. Martínez-Salgado, I. Fuentes-Calvo, B. Garcia-Cenador, E. Santos, J.M. LópezNovoa, Involvement of $\mathrm{H}$ - and $\mathrm{N}$-Ras isoforms in transforming growth factor-beta1 induced proliferation and in collagen and fibronectin synthesis, Exp. Cell. Res. 312 (2006) 2093-2106.

[17] I. Fuentes-Calvo, A.M. Blázquez-Medela, N. Eleno, E. Santos, J.M. López-Novoa, C. Martínez-Salgado, H-Ras isoform modulates extracellular matrix synthesis proliferation, and migration in fibroblasts, Am. J. Physiol. Cell. Physiol. 302 (2012) C686-C697.

[18] J.B. Gibbs, D.L. Pompliano, S.D. Mosser, E. Rands, R.B. Lingham, S.B. Singh, E.M. Scolnick, N.E. Kohl, A. Oliff, Selective inhibition of farnesyl-Protein transferase blocks ras processing in vivo, J. Biol. Chem. 268 (1993) 7617-7620.

[19] A. Ruocco, M. Santillo, M. Cicale, R. Serù, G. Cuda, J. Anrather, C. Iadecola, A. Postiglione, E.V. Avvedimento, R. Paternò, Farnesyl transferase inhibitors induce neuroprotection by inhibiting Ha-Ras signalling pathway, Eur. J. Neurosci. 26 (2007) 3261-3266.

[20] M. Sabbatini, M. Santillo, A. Pisani, R. Paterno, F. Uccello, R. Serù, G. Matrone, G. Spagnuolo, M. Andreucci, V. Serio, P. Esposito, B. Cianciaruso, G. Fuiano, E.V. Avvedimento, Inhibition of Ras/ERK1/2 signaling protects against postischemic renal injury, Am. J. Physiol. Renal. Physiol. 290 (2006) F1408-F1415.

[21] M. Sabbatini, F. Uccello, V. Serio, G. Troncone, V. Varone, M. Andreucci, T. Faga, A. Pisani, Effects of mycophenolate mofetil on acute ischaemia-reperfusion injury in rats and its consequences in the long term, Nephrol. Dial. Transplant. 25 (2010) 1443-1450.

[22] S. Anderson, T.W. Meyer, H.G. Rennke, B.M. Brenner, Control of glomerular hypertension limits glomerular injury in rats with reduced renal mass, J. Clin. Invest. 76 (1985) 612-619.

[23] B.N. Brenner, Nephron adaptation to renal injury or ablation, Am. J. Physiol. 249 (1985) F324-F337.

[24] E. Tapia, M. Franco, L.G. Sánchez-Lozada, V. Soto, C. Avila-Casado, J. Santamaría, Y. Quiroz, B. Rodríguez-Iturbe, J. Herrera-Acosta, Mycophenolate mofetil prevents arteriolopathy and renal injury in subtotal ablation despite persistent hypertension, Kidney Int. 63 (2003) 994-1002.

[25] M.J. Pires, A.B. Rodríguez-Peña, M. Arévalo, B. Cenador, S. Evangelista, A. Esteller, A. Sánchez-Rodríguez, A. Colaço, J.M. López-Novoa, Long-term nebivolol administration reduces renal fibrosis and prevents endothelial dysfunction in rats with hypertension induced by renal mass reduction, J. Hypertens. 25 (2007) 2486-2496.

[26] A. Nogueira, A.F. Rocha, M. Ginja, P.A. Oliveira, M.J. Pires, Ultrasonographic evaluation of the kidney in 5/6 nephrectomized rats: correlation with biochemical and histopathological findings, In Vivo 30 (2016) 829-834.

[27] A. Nogueira, F. Peixoto, M.M. Oliveira, C.A. Pires, B. Colaço, P.A. Oliveira, M.J. Pires, The effects of long-term chaetomellic acid a administration on renal function and oxidative stress in a rat model of renal mass reduction, Biomed. Res. Int. (2017), http://dx.doi.org/10.1155/2017/5125980.

[28] D. Forbes, H. Blom, N. Kostomitsopulos, G. Moore, G. Perretta, Euroguide On the Accommodation and Care of Animals Used for Experimental and Other Scientific Purposes, Federation of European Laboratory Animal Science Associations, London, 2007.

[29] Y.L. Tain, G. Freshour, A. Dikalova, K. Griendling, C. Baylis, Vitamin E reduces glomerulosclerosis, restores renal neuronal NOS, and suppresses oxidative stress in the 5/6 nephrectomized rat, Am. J. Physiol. Renal. Physiol. 292 (2007) F1404-1410.

[30] K. Asaba, A. Tojo, M.L. Onozato, S. Kinugasa, H. Miyazaki, K. Miyashita, Y. Uehara, Y. Hirata, K. Kimura, A. Goto, M. Omata, T. Fujita, Long-term renal prognosis of IgA nephropathy with therapeutic trend shifts, Intern. Med. 48 (2009) 883-890.

[31] M. Moubarak, H. Jabbour, V. Smayra, E. Chouery, Y. Saliba, V. Jebara, N. Fares, Cardiorenal syndrome in hypertensive rats: microalbuminuria, inflammation and ventricular hypertrophy, Physiol. Res. 61 (2012) 13-24.

[32] Y. Liu, Renal fibrosis: new insights into the pathogenesis and therapeutics, Kidney Int. 69 (2006) 213-217.

[33] Y. Qian, S.M. Sebti, A.D. Hamilton, Farnesyltransferase as a target for anticancer drug design, Biopolymers 43 (1997) 25-41.

[34] C. Kolofousi, K. Stefanidis, D.D. Cokkinos, D. Karakitsos, E. Antypa, P. Piperopoulos, Ultrasonographic features of kidney transplants and their complications: an imaging review, ISRN Radiol. (2013), http://dx.doi.org/10.5402/2013/480862.

[35] J. Buturovic-Ponikvar, A. Visnar-Perovic, Ultrasonography in chronic renal failure, Eur. J. Radiol. 46 (2003) 115-122.

[36] R. Waldherr, N. Gretz, Natural course of the development of histological lesions after 5/6 nephrectomy, Contrib. Nephrol. 60 (1988) 64-72.

[37] J. Floege, M.W. Burns, C.E. Alpers, A. Yoshimura, P. Pritzl, K. Gordon, R.A. Seifert, D.F. Bowen-Pope, W.G. Couser, R.J. Johnson, Glomerular cell proliferation and PDGF expression precede glomerulosclerosis in the remnant kidney model, Kidney Int. 41 (1992) 297-309.

[38] E.C. Muchaneta-Kubara, N. Sayed-Ahmed, A.M. el Nahas, Subtotal nephrectomy: a mosaic of growth factors, Nephron. Dial. Transplant. 10 (1995) 320-327.

[39] T.M. Coimbra, J. Carvalho, A. Fattori, C.G. da Silva, J.J. Lachat, Transforming growth factor-beta production during the development of renal fibrosis in rats with subtotal renal ablation, Int. J. Exp. Pathol. 77 (1996) 167-173.

[40] I. Ebihara, S. Suzuki, T. Nakamura, M. Fukui, Y. Yaguchi, Y. Tomino, H. Koide, Extracellular matrix component mRNA expression in glomeruli in experimental focal glomerulosclerosis, J. Am. Soc. Nephrol. 3 (1993) 1387-1397.

[41] J.C. Krepinsky, Y. Li, D. Tang, L. Liu, J. Scholey, A.J. Ingram, Stretch-induced raf-1 
activation in mesangial cells requires actin cytoskeletal integrity, Cell. Signal. 17 (2005) 311-320.

[42] J.C. Krepinsky, Y. Li, Y. Chang, L. Liu, F. Peng, D. Wu, D. Tang, J. Scholey, A.J. Ingram, Akt mediates mechanical strain-Induced collagen production by mesangial cells, Am. Soc. Nephrol. 16 (2005) 1661-1672.

[43] M.T. Grande, J.M. López-Novoa, Therapeutical relevance of MAP-kinase inhibitors in renal diseases: current knowledge and future clinical perspectives, Curr. Med. Chem. 15 (2008) 2054-2070.

[44] C. Martínez-Salgado, A.B. Rodríguez-Peña, J.M. López-Novoa, Involvement of small ras GTPases and their effectors in chronic renal disease, Cell. Mol. Life Sci. 65 (2008) 477-492.

[45] A.B. Rodríguez-Peña, M.T. Grande, N. Eleno, M. Arévalo, C. Guerrero, E. Santos, J.M. López-Novoa, Activation of Erk1/2 and Akt following unilateral ureteral obstruction, Kidney Int. 74 (2008) 196-209.

[46] J. Cheng, J.P. Grande, Transforming growth factor-beta signal transduction and progressive renal disease, Exp. Biol. Med. 227 (2002) 943-956.

[47] J. He, Y. Xu, D. Koya, K. Kanasaki, Role of the endothelial-to-mesenchymal transition in renal fibrosis of chronic kidney disease, Clin. Exp. Nephrol. 17 (2013) 488-497.

[48] J.L. Barnes, Y. Gorin, Myofibroblast differentiation during fibrosis: role of NAD(P)H oxidases, Kidney Int. 79 (2011) 944-956.

[49] C.K. Fujihara, D.M. Malheiros, J.L. Donato, A. Poli, G. de Nucci, R. Zatz, Nitroflurbiprofen, a new nonsteroidal anti-inflammatory, ameliorates structural injury in the remnant kidney, Am. J. Physiol. 274 (1998) F573-F579.

[50] C.K. Fujihara, D.M. Malheiros, R. Zatz, I.L. Noronha, Mycophenolate mofetil attenuates renal injury in the rat remnant kidney, Kidney Int. 54 (1998) 1510-1519.

[51] F.J. López-Hernández, J.M. López-Novoa, Role of TGF- $\beta$ in chronic kidney disease: an integration of tubular, glomerular and vascular effects, Cell Tissue Res. 347 (2012) 141-154.

[52] R. Dong, Q. Wang, X.L. He, Y.K. Chu, J.G. Lu, Q.J. Ma, Role of nuclear factor kappa $B$ and reactive oxygen species in the tumor necrosis factor-alpha-induced epithelial mesenchymal transition of MCF-7 cells, Braz. J. Med. Biol. Res. 40 (2007) 1071-1078.

[53] B. Lassegue, R.E. Clempus, Vascular NAD(P)H oxidases: specific features, expression, and regulation: am, J. Physiol. Regul. Integr. Comp. Physiol. 285 (2003) R277-R297.

[54] A. Sachse, G. Wolf, Angiotensin II-induced reactive oxygen species and the kidney, J. Am. Soc. Nephrol. 18 (2007) 2439-2446.

[55] M.J. Haurani, P.J. Pagano, Adventitial fibroblast reactive oxygen species as autacrine and paracrine mediators of remodeling: bellwether for vascular disease? Cardiovasc. Res. 75 (2007) 679-689.

[56] P.J. Pagano, S.J. Chanock, D.A. Siwik, W.S. Colucci, J.K. Clark, Angiotensin II induces p67phox mRNA expression and NADPH oxidase superoxide generation in rabbit aortic adventitial fibroblasts, Hypertension 32 (1998) 331-337.

[57] P.S. Gill, C.S. Wilcox, NADPH oxidases in the kidney, Antioxid. Redox Signal. 8 (2006) 1597-1607.

[58] S.A. Gaertner, U. Janssen, T. Ostendorf, K.M. Koch, J. Floege, W. Gwinner, Glomerular oxidative and antioxidative systems in experimental mesangioproliferative glomerulonephritis, J. Am. Soc. Nephrol. 13 (2002) 2930-2937.

[59] M. Santillo, P. Mondola, R. Serù, T. Annella, S. Cassano, I. Ciullo, M.F. Tecce, G. Iacomino, S. Damiano, G. Cuda, R. Paternò, V. Martignetti, E. Mele, A. Feliciello, E.V. Avvedimento, Opposing functions of Ki- and Ha-Ras genes in the regulation of redox signals, Curr. Biol. 11 (2001) 614-619.

[60] G. Cuda, R. Paternò, R. Ceravolo, M. Candigliota, N. Perrotti, F. Perticone, M.C. Faniello, F, Schepis, A. Ruocco, E. Mele, S. Cassano, M. Bifulco, M. Santillo, E.V. Evvedimento, Protection of human endothelial cells from oxidative stress: role of Ras-ERK1/2 signaling, Circulation 105 (2002) 968-974.

[61] R. Serù, P. Mondola, S. Damiano, S. Svegliati, S. Agnese, E.V. Avvedimento, M. Santillo, HaRas activates the NADPH oxidase complex in human neuroblastoma cells via extracellular signal-regulated kinase 1/2 pathway, J. Neurochem. 91 (2004) 613-622.

[62] S. Hahn, N.B. Kuemmerle, W. Chan, S. Hisano, P. Saborio, R.J. Krieg, J.C. Chan, Glomerulosclerosis in the remnant kidney rat is modulated by dietary alpha-tocopherol, J. Am. Soc. Nephrol. 9 (1998) 2089-2095.

[63] S. Hahn, R.J. Krieg, S. Hisano, W. Chan, N.B. Kuemmerle, P. Saborio, J.C. Chan, Vitamin E suppresses oxidative stress and glomerulosclerosis in rat remnant kidney, Pediatr. Nephrol. 13 (1999) 195-198. 